\title{
Hospital Clinical Del Centro's Patterns of Bacterial Resistance in Urine Cultures
}

\author{
Daniel Medina García ${ }^{1}$ and Fadia Samantha García Carranza² \\ ${ }^{1}$ Hospital Clínica del Centro, Dpto de Urgencias, Calle ojinaga \#816, col. centro C.P. 31000 Chihuahua, Chih, México. \\ 2Instituto tecnológico de Cd. Jiménez, Academia de Ciencias Básicas, Av. Tecnologico SN Ejido Las luisas, Jiménez, Chih, \\ México.
}

*Corresponding author: Daniel Medina García, Hospital Clínica del Centro, Dpto de Urgencias, Calle ojinaga \#816, col. centro C.P. 31000 Chihuahua, Chih, México

\section{Abstract}

Introduction: Urinary tract infection is one of the most prevalent diseases in clinical practice. They represent the third cause of morbidity in Mexico. It is advisable to carry out epidemiological studies in each hospital, at least once a year, in order to identify the current pattern of bacterial resistance and establish clinical practice guidelines for the empirical treatment of urinary infections. This study seeks to establish the pattern of antimicrobial resistance of urine cultures performed in patients with urinary tract infection to determine the most common uropathogens to guide the appropriate use of empirical antibiotic therapy. Methods: A descriptive, cross-sectional, retrospective study was carried out on the main etiological agents, the profile of sensitivity and resistance to antibiotics from urine cultures performed from urine samples of patients from the clinical hospital of the center in the city of Chihuahua, Mexico. from 2017 to 2019. Results: 214 urine cultures were analyzed, finding the most frequently isolated microorganisms were Gram-negative bacteria in $85 \%$ and Gram-positive bacteria in $15 \%$, of which, firstly E. coli, followed by Staphylococci spp, Klebsiella spp and Pseudomonas. A general resistance greater than $75 \%$ was found for cephalothin and ampicillin; for quinolones greater than $50 \%$, the cephalosporins: ceftriaxone $(53 \%)$, cefuroxime $(46.6 \%)$, cefotaxime $(40.78 \%)$, cefepime $(37.43 \%)$ and ceftazidime (37.43\%); trimethoprim associated with sulfamethoxazole (51.8\%), amoxicillin with clavulanic acid (42.11\%), nitrofurantoin $(28.99 \%)$ and carbapenems together with amikacin were the only antibiotics with a general resistance lower than $30 \%$. Conclusion: The importance of the urine culture registry is extended not only in patients with recurrent urinary infections, complicated or with treatment failures, but also to maintain a local registry of the most frequent uropathogens and the antimicrobial resistance patterns of the population attended.

\section{Keywords}

Urinary infection, bacterial resistance, uropathogens, urine culture, Escherichia coli, antibiotics, cephalosporins, quinolones, general urinary examination.

\section{Introduction}

Urinary tract infection (UTI) is one of the most prevalent diseases in clinical practice, being found in both hospitalized and outpatient patients around the world [1-3] They represent the third cause of morbidity in Mexico, with respiratory and gastrointestinal infections occupying the first and second place respectively [4]. In 2017, 4,474,599 new cases of urinary tract infections were diagnosed in our country $[5,6]$. Except for some microorganisms that can be found in the anterior urethra, the urinary tract is free of microorganisms, therefore their presence in the urine is likely to be indicative of infection [7].
Invasion of the healthy urinary system is restricted to a very select group of microorganisms, called "uropathogens", which are capable, through the expression of virulence factors, of bypassing or minimizing the defense mechanisms of the host [8]. In general, women are more affected by UTIs than men. It is estimated that, by the age of 24 years, $33 \%$ of women will require antimicrobial treatment for at least one episode of UTI and more than $50 \%$ will experience at least one UTI during their lifetime, in fact, $75.6 \%$ of the cases of urinary tract infections reported in 2008 in Mexico were diagnosed in female patients. 6 Women with a diagnosis of urinary tract infection have a $44 \%$ risk of becoming infected 
the following year [9-13].

The reason why the infection is more frequent in women is due to the proximity of the urethra; Furthermore, the distance between the urethra and the bladder is shorter in women and facilitates colonization of the bladder $[3,14]$. In women there are two stages in which the frequency of urinary infections increases: in sexually active women, since the colonization of the urinary tract is favored, and during pregnancy, since progesterone conditions the decrease in bladder emptying, due to its inhibitory effect on smooth muscle contraction, and there is compression of the ureteral system, with increased urinary stasis [15]. In men, it is more frequent in those over 50 years of age, secondary to obstruction by prostate growth. In the hospital environment, urinary tract infections are among the first three causes of nosocomial infections and are usually associated with the presence of urinary catheters [14].

Urinary tract infections are one of the most frequent abnormalities and cause of increased morbidity both in the hospital and in the community, so knowing the main isolated germs, as well as the resistance patterns, allows determining the variation that exists between the different bacterial species and guide the empirical initiation of antibiotics with greater elements of success [15].

In recent years, the number of bacteria that are resistant to first-line antibiotics has increased dramatically. It is defined as multi-resistant bacteria when there is bacterial resistance to 3 or more groups of antibiotics and pan-resistance when there is resistance to all the antibiotics of the ordinary antibiogram. Since the 1990s, Gram negative bacteria capable of producing enzymes that hydrolyze the beta-lactam ring of antibiotics began to emerge. These bacteria are called ESBL (Extended Spectrum Betalactamases) [16], These bacteria can be the cause of the infection acquired in the community in $14-31 \%[17,18]$ This has been associated in patients with a history of previous administration of antibiotics $[19,20]$.

The frequency of pathogen isolation and bacterial resistance vary widely depending on the different geographic regions, even between hospitals in the same country and city [21]. The World Health Organization has considered the emergence and spread of antimicrobial resistance as a priority problem and therefore since September 2001 a global measure for the containment of antimicrobial resistance (Global Strategy for Containment of Antimicrobial Resistance) was instituted, which includes as a fundamental measure the surveillance of antimicrobial susceptibility [22]. That is why it is important to publish and make known the patterns and trends of sensitivity in the different hospitals of the country and the world in order to apply or intensify strict measures of surveillance and control of the use of antibiotics [15, 23,24].

In Mexico, an incidence of multidrug resistance in urine cultures of up to $22 \%$ and pan-resistance of $0.5 \%$ has been reported. In response to the appearance of these resistant microorganisms, new drugs have been developed that are resistant to the defense mechanisms of bacteria, there are also "old" drugs that continue to be effective against bacteria, such as aminoglycosides and nitrofurantoin. It is advisable to carry out epidemiological studies in each hospital, at least once a year, in order to identify the current pattern of bacterial resistance and establish clinical practice guidelines for the empirical treatment of urinary infections [20].

Knowing the main microorganisms involved, as well as the susceptibility patterns in hospital centers, allows initiating an empirical directed antimicrobial treatment, which is very useful especially for immunosuppressed patients or with data of severe sepsis [25].

There are multiple forms of presentation, from asymptomatic bacteriuria to pyelonephritis with all the signs and symptoms that can occur in different types of patients, say pediatric, elderly, pregnant, cancer patients, etc. The mechanisms by which urinary infection occurs are varied and complex and not only depend on host factors but also on the pathogenicity mechanisms that bacteria have [26]. Uncomplicated urinary infection is one that affects subjects with a structurally normal urinary tract and whose defense mechanisms are intact [8]. UTIs can be complicated by bacteremia and sepsis, which increases morbidity and mortality, length of hospital stay, and related costs. In the last decade, an increase in resistant bacterial strains in urine was identified, both from community patients and hospitalized patients [25].

The financial burden is notable, especially in Latin American countries, where the prescription of antimicrobials is less strictly controlled. A cross-sectional study conducted in a pediatric hospital in the state of Sonora, found that the average cost of medical care per episode of nosocomial urinary infection was $\$ 2,062.00$ USD.6.

Resistance to antibiotics and appeared with the introduction of these drugs in medical institutions, and increased as it was widespread clinical use and other areas of human endeavor (livestock, aquaculture, forestry, etc.) is therefore from The emergence of antimicrobials raised concerns about the emergence of bacterial resistance to antibiotics, as was pointed out early by Fleming and

Citation: Daniel Medina García ${ }^{1}$ and Fadia Samantha García Carranza ${ }^{2}$.Hospital Clinical Del Centro's Patterns of Bacterial Resistance in Urine Cultures

Op Acc J Bio Sci \& Res 9(1)-2021 
Waksman (both Nobel Prize winners for discovering penicillin and streptomycin, respectively) who pointed out that their inappropriate use could generate resistance. bacterial infection in microorganisms with greater significance in the clinic and in public health, with a high risk of treatment failure [14]. The empirical use of antibiotics improperly in the treatment of UTIs can facilitate the development of resistanc to antimicrobial agents, which poses a great challenge for clinicians and researchers, since data on the prevalence of Uropathogens and antimicrobial susceptibility vary between care centers and cities and must be identified for each hospital [3, 27-29].

Due to their characteristics and virulence, uropathogens have for many years been subjected to the action of multiple antimicrobials: beta-lactams (with or without inhibitors), fluoroquinolones, aminoglycosides, furans, among others, all of them have been present at some point in the therapeutic schemes of UTIs, [20] which is why these bacteria have evolved resistance mechanisms that make them currently included within the group called ESCAPE together with such invasive microorganisms as Escherichia coli, Staphylococcus aureus methicillin resistant, Clostridium difficcile, Acinetobacter baumannii, Pseudomona aeruginosa and Vancomycin resistant Enterococcus [26].

The increase in antimicrobial resistance may be due, in small part, to the recommendation to initiate treatment empirically without the need for microbiological documentation in the face of predictive symptoms of low uncomplicated urinary tract infection $[27,30,31]$. On the other hand, resistance records obtained from urine culture laboratory reports tend to overestimate the true prevalence of resistance due to the selection bias inherent in the indication of these studies (patients who failed initial treatments, complicated urinary tract infections or associated resistance factors) [8,32-35] Resistance mechanisms have been thoroughly studied in E. coli and it is suspected that these are shared by the rest of the uropathogens.

Some of the mechanisms described are:

Alterations in permeability: low level of resistance, nonspecific, although it is generally accompanied by another mechanism.

Extended spectrum $\beta$-lactamase (ESBL): Class A (Ambler) Group 2b KB: TEM-1, TEM-2 and SHV-1 show resistance to ampicillin and ticarcillin. Inhibitable by sulbactam, clavulanic and tazobactam. Overproduction of TEM-1 or SHV-1 generates resistance to ampicillin, ticarcillin, amoxicillin / clavulanate, ampicillin / sulbactam, and cephalothin.
Extended spectrum $\beta$-lactamase (ESBL): Group 2be KB: TEM, SHV, CTX-M, PER, VEB, GES, OXAs. They are resistant to ampicillin, ticarcillin, piperacillin, 1st, 2nd, 3rd cephalosporins (cefotaxime, ceftriaxone, ceftazidime) and 4th generation (cefepime) and monobactams. They generally have accompanying resistance to quinolones and aminoglycosides.

Plasmid AmpC-type $\beta$ Lactamase: Class C (Ambler) - Group 1 (KB). They have the characteristic of giving resistant cefoxitin, although there are exceptions. They are inhibible by oxa / cloxa and boronic acid. They generate resistance to 3 rd generation cephalosporins and decrease in the sensitivity of 4 th generation. In the case of uncomplicated urinary tract infection, the use of sensitive 3rd generation cephalosporins in the antibiogram can be successful in treatment [36].

Quinolone resistance: Chromosomal mutations (nontransferable): Target site alterations (QRDR mutations of gyrA, gyrB, parC, parE genes). The main resistance mechanism in quinolones. Decrease in the cytoplasmic concentration of the drug (reduced permeability, E-flux)

Plasmid mechanisms (transferable):Protection of the target site (Qnr protein protects DNA gyrase and Topo IV), Enzymatic modification of ATB (enzyme AAC (6') -1b acetylates the $\mathrm{NH2}$ ), E-flux group specific for fluoroquinolones.

Carbapenemases: they are classified into serine carbapenemases, metallo $\beta$-lactamase (MBL). They are enzymes that inactivate all beta-lactam antibiotics (penicillins, cephalosporins, and carbapenems). Cut-off points to suspect the presence of carbapenemase: $C A Z \leq 22$ and $\mathrm{MER} \leq 23$ [37].

In recent years, the presence of KPC has been reported in Enterobacteria, with Klebsiella pneumoniae being the main pathogen that carries this resistance, but cases have already been detected in E. coli, C. freundii, Serratia marcescens and Enterobacter cloacae [13].

\section{Methods}

\section{Methodological Design}

Descriptive, cross-sectional, retrospective study on the main etiological agents, the profile of sensitivity and resistance to antibiotics from urine cultures performed from urine samples of patients treated in the emergency department and internal medicine of the clinical hospital of the center in the city of Chihuahua, Chihuahua, Mexico from January 8, 2017 to August 23, 2019.

\section{Data Analysis}

Citation: Daniel Medina García ${ }^{1}$ and Fadia Samantha García Carranza ${ }^{2}$.Hospital Clinical Del Centro's Patterns of Bacterial Resistance in Urine Cultures

Op Acc J Bio Sci \& Res 9(1)-2021 
The following type of analysis was performed: identification of urine cultures, of drugs evaluated for sensitivity and resistance in the antibiogram , the bacteria isolated in all the processed urine cultures and the results of the antibiograms in the clinical and microbiological laboratory of the hospital were identified throughout the study period, these urine cultures were processed using the manual Chromagar technique of the supplier Beckton Dickinson Diagnostics ( BD) with calibrated loop, incubation at $37{ }^{\circ} \mathrm{C}$ for 24 hours, including those with more than 100,000 Colony Forming Units per milliliter (CFU) in the analysis.

In addition, all cultures that had their corresponding antibiogram based on the semi-automatic MicroScan autoSCAN-4 system were evaluated. Antibiotics used for the management of UTI and Gram-positive bacterial infections were included. For data analysis, the statistical package SPSS Statistics, version 22.0 (IBM, USA) for Windows was used, descriptive statistics were used as mean, standard deviation for continuous variables and percentages for categorical variables, the test was performed of Pearson's Chi-square for the categorical ones, was determined a $p<0.05$ as a level of statistical significance, comparing the resistance and sensitivity for each antibiotic with the previous years. The protocol was submitted for approval and authorization by the president of the teaching and research committee of the Hospital Clínica del Centro in the category of research without risk, Dr. Belinda Sofía Gómez Quintana.

\section{Results}

\section{Statistical Analysis}

214 positive urine cultures were analyzed for bacterial growth, finding that the most frequently isolated microorganisms were Gram-negative bacteria in $85 \%$ and Gram-positive bacteria in 15\%, of which, in the first place, Escherichia coli, followed by Staphylococci sp, Klebsiella sp and Pseudomonas As can be seenin (Table 1) and (Figure 1).

The general resistance of the analyzed cultures that were positive for E. coli, as we can analyze in (Figure 2 ), showed a high percentage of cephalothin (94.74\%) and ampicillin (73.98\%); Antibiotics such as norfloxacin, ampicillin associated with sulbactam, levofloxacin, ciprofloxacin, cefazolin, and trimethropin associated with sulfamethoxazole, in order from highest to lowest resistance, remain between (68\% and 55\%). Between $50 \%$ and $40 \%$ are the second, third and fourth generation cephalosporins: cefuroxime, cefepime, cefotaxime, ceftazidime and ceftriaxone. Antibiotics such as amoxicillin associated with clavulanic acid, aminoglycosides (amikacin and gentamicin) and nitrofurantoin maintain low resistance (less than $30 \%$ ).
Table 1: Most frequently found pathogens in 329 urine cultures from patients with UTI.

\begin{tabular}{|c|c|c|}
\hline & Frecuencia & Porcentaje \\
\hline E Coli & 124 & 57.9 \\
\hline Estafilococo & 23 & 10.7 \\
\hline Citrobacter Spp & 6 & 2.8 \\
\hline Proteus Spp & 10 & 4.7 \\
\hline P Aeruginosa & 11 & 5.1 \\
\hline Klebsiella Spp & 17 & 7.9 \\
\hline Acinetobacter & & \\
Spp & 3 & 1.4 \\
\hline E Faecalis & 9 & 4.2 \\
\hline Enterobacter & 2 & 0.9 \\
\hline Otro & 9 & 402 \\
\hline Total & 214 & 100 \\
\hline
\end{tabular}

carbapenemic antibiotics (ertapenem and imipenem) show zero resistance (less than $5 \%$ ).

The general resistance pattern in the cultures that were analyzed and that were positive for the staphylococcal strains, as shown in (Figure 3), we found absolute resistance to ampicillin, the antibiotics amoxicillin with clavulanic acid, ampicillin associated with sulbactam, ceftriaxone, and the quinolones ciprofloxacin and levofloxacin showed resistance between 80 and $60 \%$. With an intermediate resistance between 55 and $30 \%$ are the antibiotics gentamicin, tetracycline, vancomycin and trimethoprim associated with sulfamethoxazole, it should be noted that nitrofurantoin shows a general resistance of only $30 \%$, being the most sensitive for the treatment of infections urinary tract by staphylococci.

The general resistance of the analyzed cultures that were positive for the Klebsiella strains, as we can analyze in (Figure 4), showed absolute resistance to ampicillin; antibiotics such as nitrofurantoin, cefazolin and ampicillin associated with sulbactam maintain resistance between $60 \%$ and $40 \%$. The cephalosporins cefuroxime and cefotaxime, together with amoxicillin associated with clavulanic acid, trimethoprim with sulfamethoxazole and ciprofloxacin maintain low resistances between $30 \%$ and $20 \%$. The third and fourth generation cephalosporins: cefepime, ceftazidime and ceftriaxone, together with levofloxacin maintain resistance rates of less than $20 \%$. Carbapenemic antibiotics (ertapenem and imipenem) and aminoglycosides (gentamicin and amikacin show very low resistance (less than 15\%).

Citation: Daniel Medina García ${ }^{1}$ and Fadia Samantha García Carranza ${ }^{2}$.Hospital Clinical Del Centro's Patterns of Bacterial Resistance in Urine Cultures

Op Acc J Bio Sci \& Res 9(1)-2021 


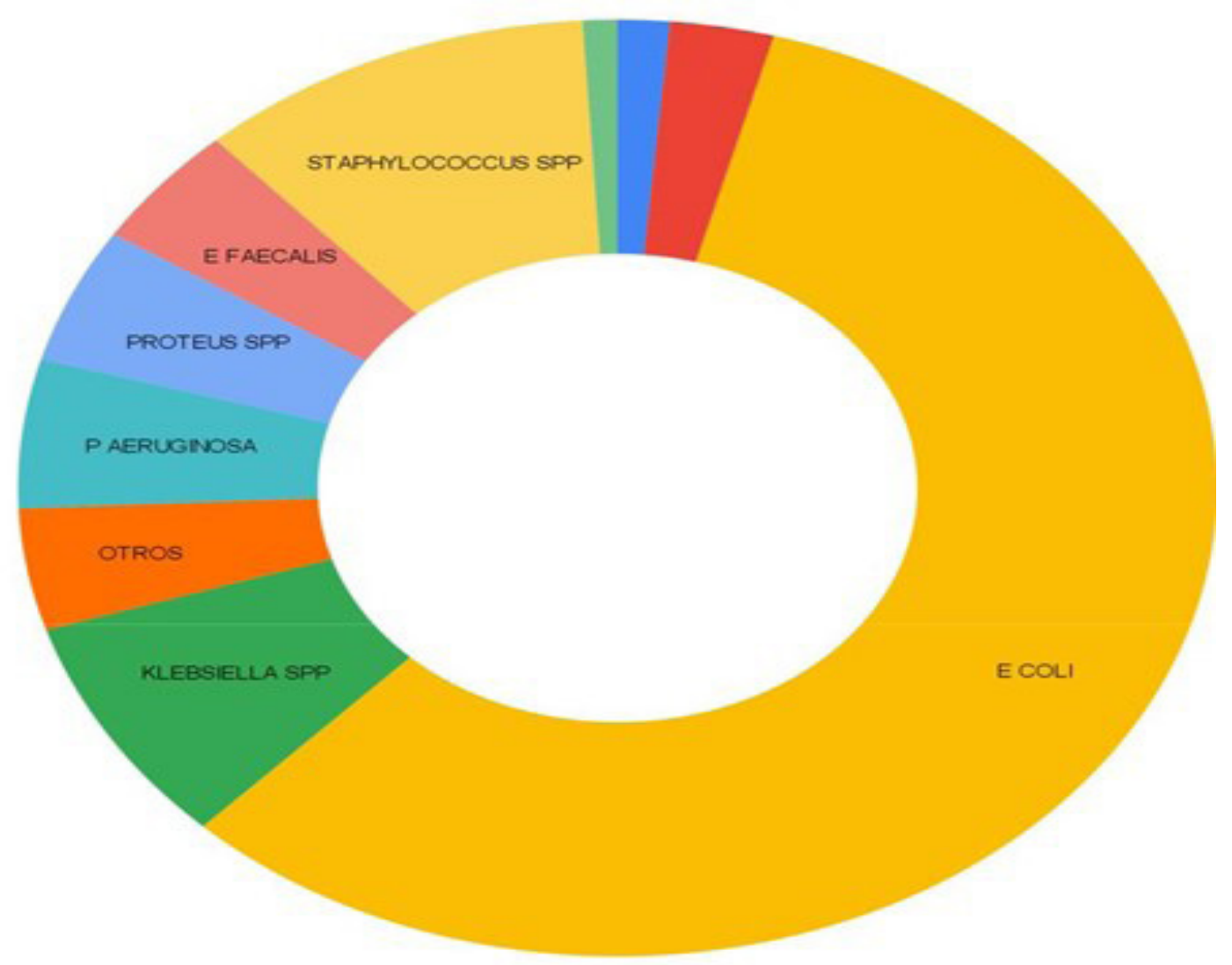

Figure 1: Most frequent pathogens in the 329 urine cultures of patients with UTI.

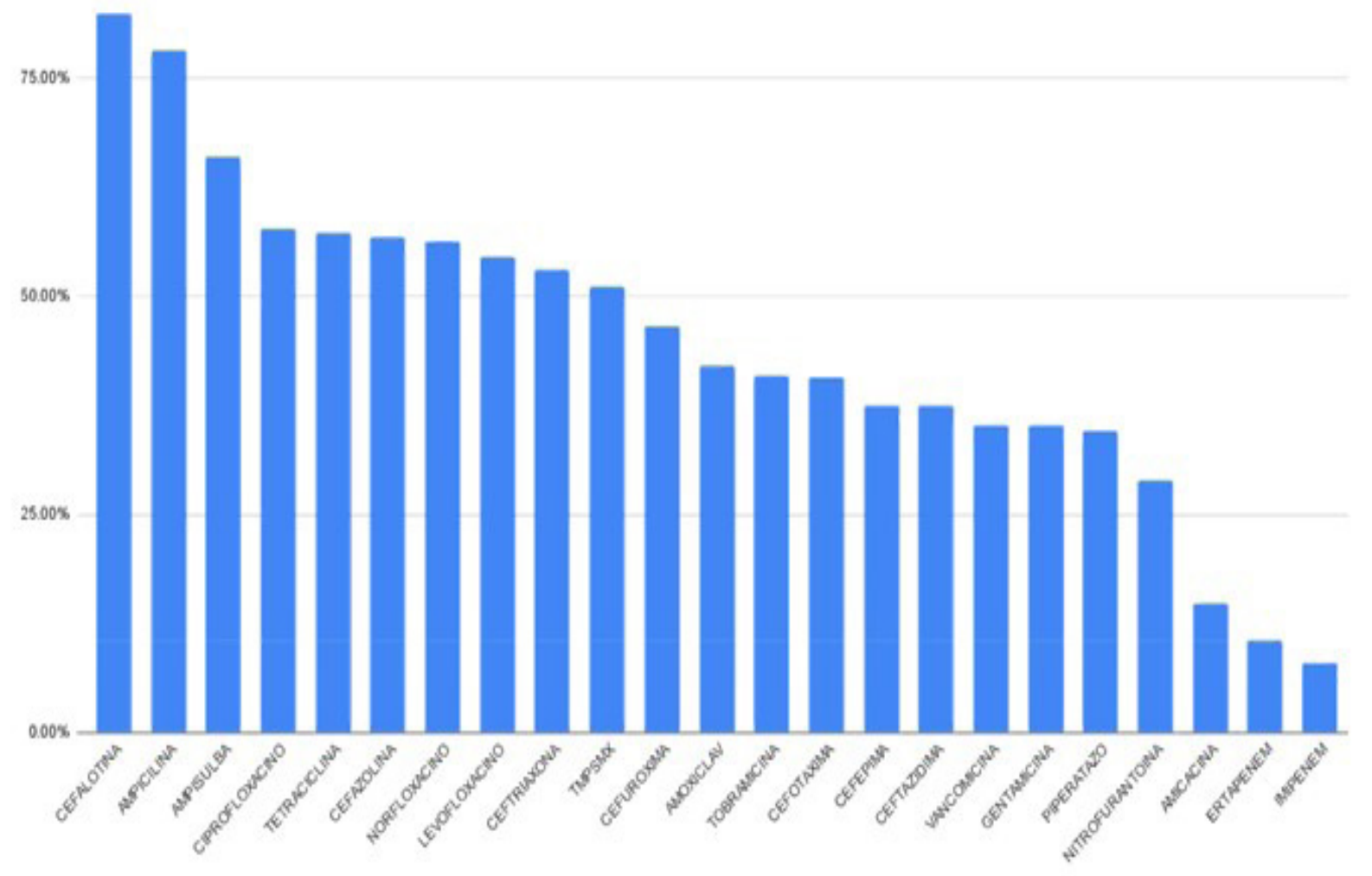

Figure 2: General antibiotic resistance in E. coli obtained from urine cultures.

Citation: Daniel Medina García ${ }^{1}$ and Fadia Samantha García Carranza ${ }^{2}$.Hospital Clinical Del Centro's Patterns of Bacterial Resistance in Urine Cultures

Op Acc J Bio Sci \& Res 9(1)-2021 
$100.00 \%$

$75.00 \%$

(c)

$50.00 \%$

$25.00 \%$

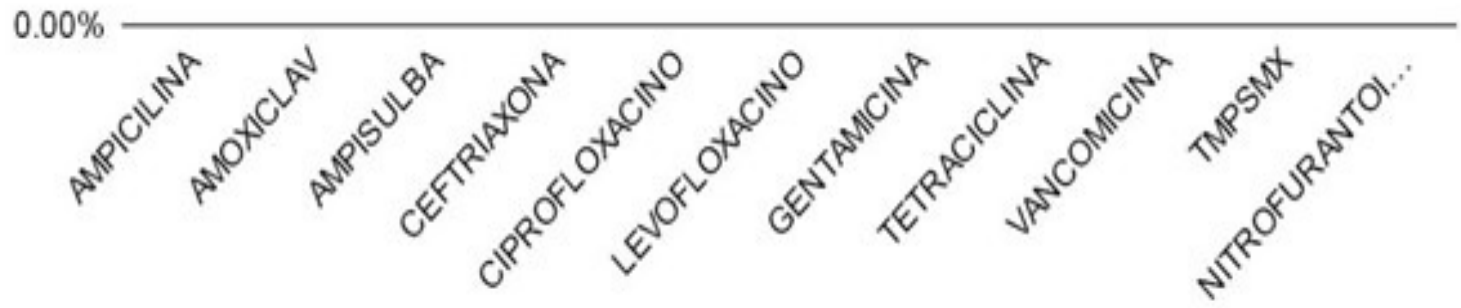

Figure 3: General antibiotic resistance in staphylococci obtained from urine cultures.

$100.00 \%$

$75.00 \%$

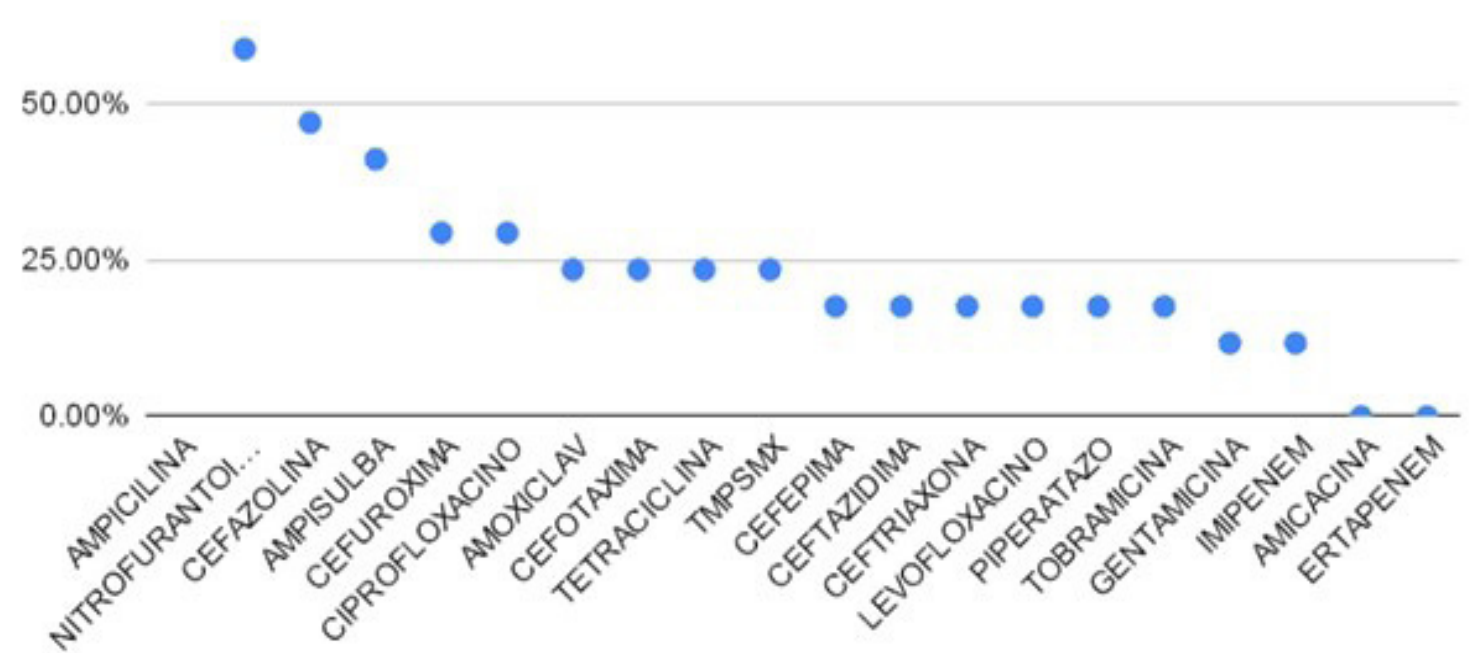

Figure 4: General antibiotic resistance in klebsiella spp obtained from urine cultures.

Citation: Daniel Medina García ${ }^{1}$ and Fadia Samantha García Carranza ${ }^{2}$.Hospital Clinical Del Centro's Patterns of Bacterial Resistance in Urine Cultures

Op Acc J Bio Sci \& Res 9(1)-2021

DOI: 10.46718/JBGSR.2021.09.000221 
Pearson's Chi-square statistical test was performed, relating the annual resistance of antibiotics compared to each year (2017, 2018 and 2019) yielded, for the following antibioticsvalues $p$ less than 0.05 , amoxicillin with acid clavulanic $(p=0.014)$, cefazolin $(p=0.027)$, trimethoprim associated with sulfamethoxazole $(p=0.037)$, nitrofurantoin $(p=0.005)$ and piperacillin with tazobactam ( $p=0.009)$; therefore we can reject the null hypothesis and it is established that there have been no changes in the resistance patterns during the years 2017 to 2019 . The data obtained for the antibiotics amikacin $(p=0.061)$, tetracycline $(p=0.070)$, cefepime $(p=0.522)$, cefotaxime $(p=0.131)$, ceftazidime $(p=0.469)$, ceftriaxone $(p=0.214)$, cefuroxime $(p=0.225)$, ertapenem $(p=0.572)$, gentamicin $(p=0.775)$, imipenem $(p=0.775)$, yieldedvalues $p$ greater than 0.05, which accepts the null hypothesis, indicating statistically significant changes in resistance patterns; however, these changes are evidently due to an increase in the antimicrobial sensitivity of uropathogens. Lastly, the antibiotics tobramycin $(p=0.427)$, ciprofloxacin $(p=0.469)$, levofloxacin $(p=0.375)$, vancomycin $(p=0.447)$, norfloxacin $(p=0.178)$, ampicillin with sulbactam ( $p$

$=0.347)$, ampicillin $(p=0.173)$, cephalothin $(p=$ 0.943 ), showedvalues $p$ higher than 0.05 , which accepts the null hypothesis, indicating statistically significant changes, but they are demonstrated in a statistically significant increase in the resistance of uropathogens to said antibiotics through time studied.

\section{Discussion}

The results obtained highlight the fact that, as reported by surveillance studies of urinary infections from other regions of the world, gram-negative bacteria are the most commonly isolated pathogens, of which Enterobacteriaceae are the most often isolated pathogens. E. coli ranked first in isolates, albeit in a lower percentage (57.9\%) compared to literature reports ( 70\%), followed by Staphylococci $(10.7 \%)$ and Klebsiella third (7.9\%).

A general resistance greater than $75 \%$ was found for cephalothin and ampicillin ( $82.35 \%$ and $78.2 \%$, respectively) for which it is recommended not to be used as therapy for urinary tract infection. In general, quinolones (levofloxacin, ciprofloxacin and norfloxacin) presented a resistance greater than $50 \%$, so it is advisable not to be used as first-line antibiotics in the treatment of uncomplicated urinary tract infections and that their use is restricted to administration intrahospital or under documentation of urine culture with sensitivity to these quinolones. Carbapenems (imipenem and ertapenem) together with amikacin were the only antibiotics with a general resistance lower than $25 \%$, for which their use is recommended in patients with urosepsis. The first generation cephalosporins cephalothin (82.35\%) and cefazolin $(56.74 \%)$ show resistance greater than $50 \%$ and are not recommended as outpatient therapy, in addition to not having oral presentations. second, third and fourth generation cephalosporins, with the exception of ceftriaxone (53\%), maintain resistances lower than $50 \%$, of which only cefuroxime $(46.6 \%)$ is found in the oral route, the rest: cefotaxime $(40.78 \%)$, cefepime $(37.43 \%)$ and ceftazidime $(37.43 \%)$ are only found in the parenteral route, so they should be used only in the hospital and not as outpatient treatment.

Trimethoprim associated with sulfamethoxazole (51.8\%) maintains relatively high general resistance, however the resistance for $E$ coli increases to $55.75 \%$, compared to the resistance, less than $50 \%$, that it presents for Klebsiella and staphylococci $(23.53 \%$ and $36.36 \%$, respectively). Amoxicillin with clavulanic acid (42.11\%) maintains a resistance lower than $50 \%$, it is in oral presentation and maintains low resistance for bacteria such as E. coli (30.89\%) and Klebsiella spp (23.53\%), however it maintains a resistance high for Gram-positive bacteria, such as streptococci (78.26\%) and enterococci; Therefore, its use is suggested empirically for urinary tract infections when it is suspected that the uropathogen belongs to the Gram-negative group. Nitrofurantoin $(28.99 \%)$ maintains a low resistance rate in general, is found in oral therapy and should be used in urinary tract infections with failure prior to treatment, with or without urine culture that confirms the sensitivity of the uropathogen, or in patients with recurrent urinary infections.

Resistance of E. coli to drugs frequently used in outpatients with urinary tract infections, such as ciprofloxacin and levofloxacin, was recognized as alarmingly high $(60.98 \%$ and $61.48 \%$, respectively); Consequently, it is possible to conclude that due to this high rate of resistance, these drugs should be left out of the arsenal of empirical therapy for urinary tract infections in the community and only be used for complicated or intrahospital urinary tract infections. Nitrofurantoin (11.76\%) remains with a low resistance, which is why it should be the initial therapy in patients with recurrent symptoms, with or without urine culture that confirms the sensitivity of the uropathogen.

\section{Recommendations}

Based on the results of the urine cultures and the difference between the resistances presented by the different types of antibiotics, we can make the following recommendations. 
1. Antibiotic therapy should be directed to the most common uropathogens in the population of the Hospital Clínica del Centro and not only directed by the literature.

2. The most common uropathogen found in the urine cultures studied was Escherichia Coli, therefore antimicrobial therapy should be directed to the less resistant antibiotics.

3. In outpatients, oral antibiotic therapy should preferably be started, with or without parenteral impregnation doses, as the case may be.

4. Nitrofurantoin has the lowest resistance to the uropathogens studied, it could be used as initial therapy in patients with recurrent symptoms or with previous unsuccessful treatment.

5. The set of trimethoprim sulfamethoxazole demonstrates use with low resistance, is in oral presentation and is a good prospect of therapy for infection first frame of tract, uncomplicated urinary and with good sensitivity for grampositivos uropathogens.

6. Ampicillin with clavulanic acid is a good therapy for gram-negative uropathogens and can be used as first-line therapy.

7. Antibiotics belonging to the quinolone group present a degree of bacterial resistance greater than $50 \%$, in addition to a statistically significant change in the increase in said resistance, for which it is suggested that their use be reserved for in-hospital patients or with antibiograms that demonstrate sensitivity .

8. Second and third generation cephalosporins show an intermediate degree of resistance, and it is suggested to avoid their use when infection by gram-positive bacteria is suspected.

9. Aminoglycosides have a low antimicrobial resistance index, however their administration is parenteral, so they can be used as second-line therapy or in patients with a history of failed treatments, recurrent urinary tract infections, or comorbidities that increase the risk of urosepsis. .

10. The importance of the urine culture registry is extended not only in patients with recurrent, complicated or treatment failure urinary infections, but also to maintain a local registry of the most frequent uropathogens and the antimicrobial resistance patterns of the population attended.

\section{References}

1. Grabe M, Bjerklund-Johansen TE, Botto H, Çek M, Naber KG, et al. (2010) Clinical guide on urological infections. Eur Assoc Urol.

2. Martínez E, Osorio J, Delgado J, Esparza GE, Motoa G, et al. (2013) Lower urinary tract infections in adults and pregnant women: consensus for empirical management. Infectio 17(3): 122-135.

3. Castrillón JD (2019) Etiology and antimicrobial resistance profile in patients with urinary tract infection. Infectio 23(1): 45-51.

4. Soto G, Moreno L, Pahua D (2016) Epidemiological panorama of Mexico, main causes of morbidity and mortality. Revista de la Facultad de Medicina de la UNAM 59(6)8: 22.

5. Páramo F, Tovar A, Rendón M (2015) Resistencia antimicrobiana en pacientes con infección de vías urinarias hospitalizados en el servicio de Medicina Interna del Nuevo Sanatorio Durango, de enero a diciembre de 2013. Med Int Méx 31(1): 34-40.

6. Luis VA (2017) Urinary tract infection etiology and antimicrobial sensitivity in a Mexican hospital from 2010 to 2015. Rev Mex Urol 97105.

7. Picazo J. J editor, La infección urinaria (2002) SEIMC.

8. ETIOLOGÍA Y RESISTENCIA A ANTIMICROBIANOS DE LA INFECCIÓN NO COMPLICADA DEL TRACTO URINARIO (2017). Guillermo Bertoni;María Graciela Guerrini;Aníbal Calmagg;Fernanda Barberis;Laura Gorge;Pablo Bonvehi;Elena Temporit;Fabián Herrera;Mora Obed;Belén Alcorta;Juan Farías;Analía MYKIETIUK. MEDICINA (Buenos Aires), 304-308.

9. Schito GC, Naber KG, Botto H, Palou J, Mazzei T, et al. (2009) The ARESC study: an international survey on the antimicrobial resistance of pathogens involved in uncomplicated urinary tract infections. Int J Antimicrob Agents 34: 407-413.

10. Lindsay N (2008) Uncomplicated Urinary Tract Infections in Adults. Urol Clin N Am 35: 1-12.

11. Chung A, Arianayagam M, Rashid P (2010) Bacterial cystitis in women. Aust Fam Physician 39: 295-298.

12. Aparicio A, Rodríguez S, Tobar V, Iregui JD, Hernández CE (2010) Frecuencia reportada de infección de vías urinarias no complicada en mujeres universitarias. Urol Colomb XIX: 31-37.

13. Ruiz, CY (sf). Resistencia antimicrobiana de E. coli aisladas de urocultivos en pacientes ambulatorios . Obtenido de Universidad Nacional del Nordeste. Facultad de Medicina.

14. Gómez Toscano V, Martinez Oroszco JA, Gonzalez Lara MF, Matias Juan NA, Martin-Oraet Arciniegas A (2019) 100 preguntas clave en resistencia a antibióticos. Permanyer.

15. Juárez, PC, Acosta, CV, Sandoval, S., Gordillo, P., \& Fernández, PV (2007) Patrones de resistencia bacteriana en urocultivos en un hospital oncológico. MEDIGRAPHIC 330-336.

16. Chavolla A, González M, Ruiz O (2016) Prevalencia de bacterias aisladas con resistencia antibiótica extendida en los cultivos de orina durante 8 años en un hospital de segundo nivel en México. Rev Mex Urol. 76(4): 213-217.

17. Galindo M (2018) Caracterización molecular y patrón de susceptibilidad antimicrobiana de Escherichia coli productora de B-lactamasas de espectro extendido en infección del tracto urinario adquirido en la comunidad. Rev Chilena Infectol 35(1): 29-35.

18. Ponce A, Rodríguez E, Mortín R, Cornejo DP, Tinoco JC, et al. (2018) Antimicrobial susceptibility of gramnegative bacilli isolated from intraabdominal and urinary tract infections in Mexico from 2009 to 2015: Results from the Study for Monitoring Antimicrobial Resistance Trends (SMART). PloS ONE 13(6): e0198621.

19. Jaimes AM, Solís E (2017) Administración previa de antibiótico como factor asociado con infección urinaria por E. coli productora de BLEE de origen comunitario en pacientes diabéticos. Med Int Méx 33(5): 605611.+

20. Garza-Montúfar, ME, Treviño-Valdez, PD, \& Garza-Salinas, LH (2018) Resistencia bacteriana y comorbilidades presentes en pacientes urológicos ambulatorios con urocultivos positivos. Rev Med Inst Mex Seguro Soc 347-353.

21. Turnidge J, Bell J, Biedenbach DJ, Jones RN (2002) Pathogen occurrence and antimicrobial resistance trends among urinary tract infection isolates in the Asia-Western pacific region: report form the SENTRY 
Antimicrobial Surveillance Program, 1998-1999. Int J Antimicrob Agents 20:10-17.

22. World Health Organization-Antimicrobial resistance. (2002) Fact sheet $\mathrm{N}^{\circ} 194$.

23. Goldmann DA, Huskins WC (1997) Control of nosocomial antimicrobial resistant bacteria: a strategy priority for hospitals worldwide. Clin Infect Dis 24(suppl 1): S139-S145.

24. Oplustil CP, Nunes R, Mendes C, RESISTNET Group. (2001) Multicenter evaluation of resistance patterns of Klebsiella pneumoniae, Escherichia coli, Salmonella spp and Shigella spp isolated from clinical specimens in Brazil. RESISTNET Surveillance Program. Braz J Infect Dis 5: 8-12.

25. Acosta, CV, Juárez, PC, \& Fernández, PV (2016) Resistencia bacteriana de cultivos de orina en un hospital oncológico:seguimiento a diez años. Salud pública de méxico 446-452.

26. Trueba BS, Samper YM, Espinosa F, Casares MH, Rodríguez NL (2014) Susceptibilidad antimicrobiana y mecanismos de resistencia de Escherichia coli aisladas a partir de urocultivos en un hospital de tercer nivel . Revista Cubana de Medicina 3-13.

27. Leal AL, Cortés JA, Arias G, Ovalle MV, Saavedra SY, et al. (2013) Emergence of resistance to third generation cephalosporins by Enterobacteriaceae causing community-onset urinary tract infections in hospitals in Colombia. Enferm Infecc Microbiol Clin 31: 298-303.

28. Murillo-Rojas OA, Leal-Castro AL, Eslava-Schmalbach JH (2006) Using antibiotics in urinary tract infection in a first level of attention health care unit in Bogotá, Colombia. Rev Salud Pública 8: 170-81.

29. Barranco LC (2007) Infecciones de vías urinarias en el Hospital Universidad del Norte. Salud Uninorte 23(1): 9-18.
30. Hooton TM (2012) Uncomplicated urinary tract infection. N Engl J Med 366: 1028-1037.

31. Gupta K, Hooton TM, Naber KG (2011) International clinical practice guidelines for the treatment of acute uncomplicated cystitis and pyelonephritis in women: a 2010 update by the Infectious Diseases Society of America and the European Society for Microbiology and Infectious Diseases. Clin Infect Dis 52: e102-e120.

32. Echevarria-Zarate J, Sarmiento E, Osores-Plengue F (2006) Infección del tracto urinario y manejo antibiótico. Acta méd. Peruana, ene./abr 23(1): 26-31.

33. Ti TY, Kumarasinghe G, Taylor MB (2003) What is true communityacquired urinary tract infection? Comparison of pathogens identified in urine from routine outpatient specimens and from community clinics in a prospective study. Eur J Clin Microbiol Infect Dis 22: 242-245.

34. Astete La Madrid S, Flores-Fukuda F, Buckley De Meritens A (2004) Sensibilidad antibiótica de los gérmenes causantes de infecciones urinarias en pacientes ambulatorios en el Hospital Nacional Arzobispo Loayza. Rev Soc Per Med Inter 17: 5-8.

35. Machado-Alba JE, Murillo-Muñoz MM (2012) Evaluación de sensibilidad antibiótica en urocultivos de pacientes en primer nivel de atención en salud de Pereira. Rev. salud pública 2012.

36. Galas M (2015) Optimización de las pruebas de sensibilidad de los agentes etiológicos de infecciones ambulatorias. En: XVI Jornadas Argentinas de Microbiología y III Congreso Bioquímico del Litoral.

37. Whonet Argentina (2014) [en línea] Protocolo WHONET consensuado . Agosto de 2014. Disponible en.

*Corresponding author: Daniel Medina García, Email: danielmedinagarcia26@gmail.com

Next Submission with BGSR follows:

- Rapid Peer Review

- Reprints for Original Copy

- E-Prints Availability

- Below URL for auxiliary Submission Link: https://biogenericpublishers.com/submit-manuscript/ 